\title{
Response of $\mathrm{OH}$ airglow emissions to mesospheric gravity waves and comparisons with full-wave model simulation at a low-latitude Indian station
}

\author{
Rupesh N. Ghodpage ${ }^{1}$, Michael P. Hickey ${ }^{2}$, Alok K. Taori ${ }^{3, \text { a }}$, Devendraa Siingh ${ }^{4}$, and Parashram T. Patil ${ }^{1}$ \\ ${ }^{1}$ Indian Institute of Geomagnetism, Shivaji University Campus, Kolhapur 416004, India \\ ${ }^{2}$ Embry-Riddle Aeronautical University, Daytona Beach, FL 32114, USA \\ ${ }^{3}$ National Atmospheric Research Laboratory, Pakala Mandal, Gadanki 517112, India \\ ${ }^{4}$ Indian Institute of Tropical Meteorology, Pune-411 008, Maharashtra, India \\ anow at: National Remote Sensing Centre (NRSC), Hyderabad 500037, India
}

Correspondence to: Alok K. Taori (alok.taori@gmail.com)

Received: 12 October 2015 - Published in Atmos. Chem. Phys. Discuss.: 21 December 2015

Revised: 5 April 2016 - Accepted: 17 April 2016 - Published: 4 May 2016

\begin{abstract}
Quasi-monochromatic gravity-wave-induced oscillations, monitored using the mesospheric $\mathrm{OH}$ airglow emission over Kolhapur $\left(16.8^{\circ} \mathrm{N}, 74.2^{\circ} \mathrm{E}\right)$, India, during January to April 2010 and January to December 2011, have been characterized using the Krassovsky method. The nocturnal variability reveals prominent wave signatures with periods ranging from 5.2 to $10.8 \mathrm{~h}$ as the dominant nocturnal wave with embedded short-period waves having wave periods of 1.5-4.4h. The results show that the magnitude of the Krassovsky parameter, viz. $|\eta|$, ranged from 2.1 to $10.2 \mathrm{~h}$ for principal or long nocturnal waves $(5.2-10.8 \mathrm{~h}$ observed periods), and from 1.5 to $5.4 \mathrm{~h}$ for the short waves $(1.5-4.4 \mathrm{~h}$ observed periods) during the years of 2010 and 2011, respectively. The phase (i.e., $\Phi$ ) values of the Krassovsky parameters exhibited larger variability and varied from -8.1 to $-167^{\circ}$. The deduced mean vertical wavelengths are found to be approximately $-60.2 \pm 20$ and $-42.8 \pm 35 \mathrm{~km}$ for longand short-period waves for the year 2010. Similarly, for 2011 the mean vertical wavelengths are found to be approximately $-77.6 \pm 30$ and $-59.2 \pm 30 \mathrm{~km}$ for long and short wave periods, respectively, indicating that the observations over Kolhapur were dominated by upward-propagating waves. We use a full-wave model to simulate the response of $\mathrm{OH}$ emission to the wave motion and compare the results with observed values.
\end{abstract}

\section{Introduction}

Airglow hydroxyl emissions $(\mathrm{OH})$ have been widely used for studying atmospheric temperature variation in the mesopause region since the pioneering work of Meinel (1950) due to its usefulness in deriving the rotational temperature (Greet et al., 1998; Bittner et al., 2000). The collision frequency of $\mathrm{OH}$ with the neutral atmosphere in the neighborhood of $90 \mathrm{~km}$ altitude should be on the order of $10^{4} \mathrm{~s}^{-1}$, and the lifetime of the excited hydroxyl emission is around 3 to $10 \mathrm{~ms}$ (Mies, 1974). This ensures that the excited OH molecules in the rotational energy levels are in a thermal equilibrium with the atmospheric ambient gases (Sivjee and Hamwey, 1987; Takahashi et al., 1998). Thus, it is normally assumed that the rotational state of $\mathrm{OH}$ band is in a Maxwell-Boltzmann distribution. The radiated light intensity provides a direct measure of $\mathrm{OH}$ quantum state distribution in the mesopause. Meriwether (1975) arrived at an expression for the P1(2) and P1 (5) rotational lines of $\mathrm{OH}(8-3)$ band by making use of the vibration-rotation transition probabilities of Mies (1974). Therefore, using two lines from a single band, we can estimate the rotational temperature with the following equation (Mies, 1974):

$$
T_{\mathrm{n}, \mathrm{m}}=\frac{E_{v^{\prime}}\left(J_{\mathrm{m}}^{\prime}\right)-E_{v^{\prime}}\left(J_{\mathrm{n}}^{\prime}\right)}{k \ln \left[\frac{I_{\mathrm{n}}}{I_{\mathrm{m}}} \frac{A\left(J_{\mathrm{m}}^{\prime}, v^{\prime} \rightarrow J_{\mathrm{m}+1}^{\prime \prime}, v^{\prime \prime}\right)}{A\left(J_{\mathrm{n}}^{\prime}, v^{\prime} \rightarrow J_{\mathrm{n}+1}^{\prime \prime}, v^{\prime \prime}\right)} \frac{2 J_{\mathrm{m}}^{\prime}+1}{2 J_{\mathrm{n}}^{\prime}+1}\right]},
$$


where $T_{\mathrm{n}, \mathrm{m}}$ is the rotational temperature calculated from two line intensities, $I_{\mathrm{n}}$ and $I_{\mathrm{m}}$, and from rotational levels $J_{\mathrm{n}}^{\prime}$ and $J_{\mathrm{m}}^{\prime}$ in the upper vibrational level $v^{\prime}$ to $J_{\mathrm{n}+1}^{\prime \prime}$ and $J_{\mathrm{m}+1}^{\prime \prime}$ in the lower vibrational level $v^{\prime \prime} . E_{v}(J)$ is the energy of the level $(J, v) . A\left(J_{\mathrm{n}}^{\prime}, v^{\prime} \rightarrow J_{\mathrm{n}+1}^{\prime \prime}, v^{\prime \prime}\right)$ is the Einstein coefficient, for the transition from $J_{\mathrm{n}}^{\prime}, v^{\prime}$ to $J_{\mathrm{m}}^{\prime \prime}, v^{\prime \prime}$. The intensity ratio between P1 (2) and P1 (5) lines of the $\mathrm{OH}(8-3)$ band was used to obtain rotational temperature using the transition probabilities as given by Mies (1974). Often the observed temporal variations in the mesospheric hydroxyl $\mathrm{OH}$ night airglow intensities and rotational temperatures are caused by propagating gravity waves from the lower to the upper atmosphere.

The interaction of these upward-propagating waves with the ambient and other waves contributes to the dynamical variability, which in turn is reflected in observed airglow intensity and temperature perturbations (Hines, 1997). Krassovsky (1972) introduced a quantity " $\eta$ " to characterize the wave-induced perturbations. This parameter, termed "Krassovsky's parameter", is now defined as $\eta=|\eta| e^{-i \Phi}$, where $|\eta|$ indicates the ratio of the amplitude variation between the emission intensity and temperature perturbations normalized to their time averages and $\Phi$ is the phase difference between the intensity wave and its temperature counterpart (e.g., Walterscheid et al., 1987; Taylor et al., 1991). It should also be mentioned that, apart from the pure dynamical processes, $\eta$ can also be affected by various other unknown parameters, such as the variation in local oxygen photochemistry (Hickey et al., 1993) and height variation in the emission layer, which affects emission rates and temperature directly (Liu and Swenson, 2003; Vargas et al., 2007). Although above processes complicate the studies of Krassovsky's parameter, it offers an opportunity to study the above aspects. Overall, once the physics and chemistry of emissions are well understood, the $\eta$ values would offer a good tool to study the perturbations caused in a parameter (temperature, brightness/intensity) by measuring one under the assumption that gravity-wave-induced perturbations are of adiabatic nature.

Utilizing the above, many investigators have carried out observational as well as theoretical studies on the identification and characterization of gravity wave and tidal signatures with wave periodicities ranging from a few minutes to several hours (e.g., Walterscheid et al., 1987; Hecht et al., 1987; Hickey, 1988; Taylor et al., 1991; Takahashi et al., 1992; Reisin and Scheer, 1996; Taori and Taylor, 2006; Guharay et al., 2008; Ghodpage et al., 2012, 2013). However, observational studies of the magnitude and phase of $\eta$ over a range of wave periods for a given location and season are sparse. Some of the notable observations of $\eta$ for $\mathrm{OH}$ emission have been performed by Viereck and Deehr (1989) in the wave period range of $\sim 1-20 \mathrm{~h}$ and by Reisin and Scheer (1996) near to the semidiurnal tidal fluctuations.

In the present work, we utilize the mesospheric $\mathrm{OH}$ emission intensity and temperature data obtained during JanuaryApril 2010 and January-December 2011, when clear and moonless nights allowed observations to exceed $5 \mathrm{~h}$ duration. We deduce the Krassovsky parameters as a function of observed wave period and also infer the vertical wavelengths for the observed mesospheric waves. Further, we compare our estimates with the earlier results reported by various investigators. We also employ a full-wave model to simulate the effects of wave motions on the $\mathrm{OH}$ airglow. This model has been used previously to compare observations and theory of airglow fluctuations (e.g., Hickey et al., 1998; Hickey and $\mathrm{Yu}, 2005)$. Here, the model is used to estimate the values of the amplitudes and phases of Krassovsky's ratio which are compared to those derived from the observations, making the present study unique as such model comparison over India has not been done before.

\section{Instrumentation and observations}

The mesospheric $\mathrm{OH}$ observations are made using the multispectral photometer from Kolhapur $\left(16.8^{\circ} \mathrm{N}, 74.2^{\circ} \mathrm{E}\right)$ (Ghodpage et al., 2013, 2014). We analyze the data from January-April 2010 and January-December 2011, when clear-sky conditions prevailed for several nights. For the year 2010, 13 of 45 nights of observation clearly showed wavelike features, while 29 of 60 nights of data exhibited wavelike variations in 2011.

\subsection{The multispectral photometer}

Regular observations of the night airglow emissions, OI 630.0, OI $557.7 \mathrm{~nm}$, and $\mathrm{OH}$ Meinel $(731$ and $740 \mathrm{~nm}$ ) band have been carried out at the low-latitude station Kolhapur. We have operated multispectral photometer pointing to the zenith over Kolhapur. The filters have a bandwidth of $1 \mathrm{~nm}$ and their temperature is controlled at $24^{\circ} \mathrm{C}$ by a temperature controller. The temperature coefficient of filter is $0.011 \mathrm{~nm}^{\circ} \mathrm{C}^{-1}$. At $24^{\circ} \mathrm{C}$ the transmission efficiency of filters is $40-70 \%$. We kept the integration time for each filter at $15 \mathrm{~s}$, which results in repetition time of $90 \mathrm{~s}$ with an accuracy of approximately $\pm 0.5 \%$ for line intensity. The photometer has $f / 2$ optics with $\sim 10^{\circ}$ full field of view. The stepper motor rotation and sensing of the initial position are performed by computer-controlled software. As the detector, the EMI9658B photomultiplier tube is used. An amplifier (high-gain transimpedance) is used to convert and amplify the very weak photomultiplier output current (in the range of $\mathrm{nA}$ ) into corresponding voltage form. In the absence of standard calibration source, we have used relative intensities (arbitrary units). In order to study the wave features present in the mesosphere-lower thermosphere region, we consider clear-sky nights having more than $5 \mathrm{~h}$ of continuous $\mathrm{OH}$ band data as mentioned in earlier reports (e.g., Taori et al., 2005). 


\subsection{Full-wave model}

The full-wave model is a linear, steady-state model that solves the linearized Navier-Stokes equations on a highresolution vertical grid to describe the vertical propagation of acoustic-gravity waves in a windy background atmosphere including molecular viscosity and thermal conduction, ion drag, Coriolis force, and the eddy diffusion of heat and momentum in the mesosphere. The model description, including equations, boundary conditions, and method of solution, has been described elsewhere (Hickey et al., 1997; Walterscheid and Hickey, 2001; Schubert et al., 2003). The neutral perturbations are used as input to a linear, steady-state model describing $\mathrm{OH}$ airglow fluctuations (Hickey and $\mathrm{Yu}, 2005$ ).

The model solves the equations on a high-resolution vertical grid subject to boundary conditions and generally allows for the propagation in a height-varying atmosphere (nonisothermal mean state temperature and height-varying mean winds and diffusion). The linearized equations are numerically integrated from the lower to the upper boundary using the tri-diagonal algorithm described by Bruce et al. (1958) and Lindzen and Kuo (1969). The lower boundary is set well below the region of interest and a sponge layer is implemented to avoid effects of wave reflection in the airglow response. In this study the lower boundary (the bottom of the lower sponge layer) is placed at $250 \mathrm{~km}$ below $z=0$ (i.e., $-250 \mathrm{~km}$ ). The wave forcing is through the addition of heat in the energy equation. The heating is defined by a Gaussian profile with a full width at half maximum of $0.125 \mathrm{~km}$. It is centered at an altitude of $10 \mathrm{~km}$. A Rayleigh-Newtonian sponge layer, in addition to natural absorption by viscosity and heat conduction, prevents spurious reflection from the upper boundary. At the upper boundary (here $300 \mathrm{~km}$ altitude) a radiation condition is imposed using a dispersion equation that includes viscous and thermal dissipation (Hickey and Cole, 1987). The mean state is defined using the Mass Spectrometer Incoherent Scatter (MSIS) model (Hedin, 1991).

A set of linear perturbation equations for the minor species involved in the $\mathrm{OH}$ emission chemistry is solved using the approach described in Hickey (1988). This assumes that these minor species have the same velocity and temperature perturbations as the major gas (which are deduced from the full-wave model). A vertical integration of the volume emission rates through the vertical extent of the $\mathrm{OH}$ layer provides the brightness and brightness-weighted temperature perturbations, from which Krassovsky's ratio is determined. The $\mathrm{OH}$ chemistry we use is the same as that used previously (Hickey et al., 1997) and is for the OH (8-3) emission. We also determine the vertical wavelength at the peak of the $\mathrm{OH}$ emission layer evaluated from the phase variations in the temperature perturbations determined by the full-wave model.

\subsection{Spaceborne measurements}

The Sounding of the Atmosphere using Broadband Emission Radiometry (SABER) instrument, onboard the Thermosphere Ionosphere Mesosphere Energetic and Dynamics (TIMED) satellite, is a high-precision broadband radiometer which measures limb radiance (orbital inclination at $74^{\circ}$ ) of the terrestrial atmosphere in 10 selected spectral bands ranging from 1.27 to $15 \mu \mathrm{m}$. In the present study, we note larger values of $|\eta|$ occur during 2011 compared to 2010 for long/principal waves, which indicates a larger intensity to temperature perturbation ratio over Kolhapur during the passage of the waves during 2011. This could be due to the differences in either the background atmosphere or the dynamical processes. To identify the differences in the $\mathrm{OH}$ emission layer in year 2010 and 2011, we scrutinize the $\mathrm{OH}$ volume emission rate profile for Kolhapur region obtained from SABER. The selected latitude-longitude grids are 10 to $20^{\circ} \mathrm{N}$ and 70 to $90^{\circ} \mathrm{E}$, representing Kolhapur. The criteria for the selection of SABER data are such that the SABER pass should be during typical observation times (excluding twilight time).

\section{Results and discussion}

To identify the wave structures in the data, we utilize the perturbation amplitudes normalized to their time-averaged values (hereafter referred to as mean values) in the intensity and temperature data to calculate the Krassovsky ratio. To illustrate this, we show a typical example corresponding to the data obtained on 26-27 January 2011 in Fig. 1. We plot the intensity deviations from their mean values in Fig. 1a, while the temperature deviations from their mean values are plotted in Fig. 1b. We note that night airglow intensity variations show a long-period wave with embedded short-period oscillatory features. On this night, the mean airglow intensity is found to be $\sim 1.83$ arbitrary units and the mean temperature value is $\sim 195.75 \mathrm{~K}$. To identify the nocturnal variability plotted together with data as solid red lines are results of the best-fit cosine model (e.g., Taori et al., 2005) described as follows:

$Y=A \cos \left[\pi \frac{\left(X-X_{\mathrm{c}}\right)}{T}\right]$,

where $A$ is the amplitude of the fitted wave of half-period $T$ with phase $X_{\mathrm{c}}$ and $X$ is the time. The solid red lines in Fig. 1 show the results of the best-fit cosine model. We observed the presence of $\sim 8.2 \pm 1.1$ and $8 \pm 1.3 \mathrm{~h}$ waves with relative amplitudes (normalized to their mean values and converted to corresponding percent amplitude) $\sim 3.60$ and $25.64 \%$, in the nocturnal temperature and intensity variability, respectively. Given the uncertainties involved in the observations, we consider these to be the same waves. Further, we compute the $|\eta|$ value for this wave to be $7.12 \pm 1.2$. To identify the shorter 
period features in the data we obtain residuals from the bestfit model values. Figure $11 \mathrm{c}$ and $\mathrm{d}$ show the nocturnal variability of the residual intensity and temperature, respectively. The best-fit model reveals the presence of $\sim 4.2 \pm 0.2$ and $3.0 \pm 0.8 \mathrm{~h}$ wave in the temperature and intensity residuals, respectively. Once again we treat these as the same wave for the reason explained above. The best-fit analysis shows the amplitudes of this wave to be $\sim 1.019$ and $3.75 \%$ arbitrary units in the temperature and intensity data, respectively. Hence, the $|\eta|$ value for short-period waves is estimated to be $3.68 \pm 0.9$. In general we note that, in the worst case, the maximum error in $|\eta|$ values is $<25 \%$. The phase difference between the intensity and temperature waves is obtained with the help of best-fit parameters, which were also verified with a cross-correlation analysis. The phase of the principal waves (maxima) (period $\sim 8.2 \mathrm{~h}$ ) was $\sim 24.88 \mathrm{~h}$ in the temperature data and $24.4 \mathrm{~h}$ in the intensity data, which results in the phase difference of $\sim 0.48 \mathrm{~h}$, i.e., $\Phi$ values of $-21.07 \pm 12^{\circ}$. Similarly, for the shorter period (period $\sim 4.2 \mathrm{~h}$ ) the $\Phi$ values are estimated to be $-114.3 \pm 20^{\circ}$.

We can also estimate the vertical wavelength with the help of Krassovsky's parameter following the approach elaborated by Tarasick and Hines (1990).

$\lambda z=\frac{2 \pi \gamma H}{(\gamma-1)|\eta| \sin (\varphi)}$,

where $\gamma=C_{\mathrm{p}} / C_{\mathrm{v}}=1.4$ is the ratio of specific heats and $H=6 \mathrm{~km}$ is the scale height. This formula is valid for zenith observations and for plane waves. It is not valid for the evanescent waves. In Eq. (2), negative vertical wavelength corresponds to downward phase propagation (i.e., upward energy propagation), meaning that temperature oscillations precede the intensity oscillations in phase (e.g., Takahashi et al., 1990). Using the above relation we find that vertical wavelengths for the two cases discussed above are $\sim-51.5 \pm 15$ and $-39.3 \pm 40 \mathrm{~km}$ for the long- and shortperiod waves, respectively. Note that the long-period wave estimates may be biased when the data length is comparable to that of the wave period; therefore, in our study we have considered only those waves whose periods are substantially less than the length of the available data.

The above analysis was carried out on nighttime events recorded during 2010 and 2011 when the prominent wave features were visible. During the 2010 period, the principal nocturnal waves in the data show the wave periods vary from 5.2 to $10.8 \mathrm{~h}$ with corresponding temperature amplitudes ranging from 2 to $13.8 \mathrm{~K}$. Similarly, for 2011, wave periods vary between 5.2 and $8.4 \mathrm{~h}$, with corresponding temperature amplitudes lying between 1.1 and $15.7 \mathrm{~K}$. However, the intensity amplitudes of the principal waves vary from 7.9 to $49.9 \%$ and 5 to $90 \%$ for 2010 and 2011, respectively. We note that the estimated $|\eta|$ values were found to range from 2.1 to 10.5 for the principal wave. In the case of the shortperiod waves, the periods ranged from 1.5 to $4.4 \mathrm{~h}$ (for 2010) and 2.8 to $4.4 \mathrm{~h}$ (for 2011), with corresponding temperature amplitudes ranging from 0.68 to $12.2 \mathrm{~K}$ and 0.4 to $14.2 \mathrm{~K}$. The corresponding intensity amplitudes fall in range between $\sim 1.54$ and $46.8 \%$ and 1.32 and $46.8 \%$ for 2010 and 2011, respectively. The phase $(\Phi)$ values also exhibit large variability for long-period (short-period) waves range between -27 and $-167^{\circ}\left(-27\right.$ and $\left.-150^{\circ}\right)$ for 2010 and -8.1 and $-65.2^{\circ}$ $\left(-39.1\right.$ and $\left.-122.6^{\circ}\right)$ for 2011 . For 2010 the deduced vertical wavelengths are found to vary from -32.2 to $-140 \mathrm{~km}$ and -24 to $-88 \mathrm{~km}$ for the long- and short-period waves, respectively. Similarly, for 2011 the deduced vertical wavelengths are found to vary from -40 to $-102 \mathrm{~km}$ and -26 to $-92.4 \mathrm{~km}$ for the long- and short-period waves, respectively.

In Fig. 2a we plot our results for $|\eta|$ (hereafter $\eta$ ) with pink half-filled squares indicating the estimates for the year 2010 and green half-filled squares for the year 2011. We plot $\Phi$ in Fig. 2b using the same symbols as used in Fig. 2a. For a comparison, we also show the values of $\eta$ and $\Phi$ reported by other investigations (Viereck and Deehr, 1989; Takahashi et al., 1992; Oznovich et al., 1995, 1997; Drob 1996; Reisin and Scheer 1996; Taylor et al., 2001; Lopez-Gonzalez et al., 2005). Also shown in the figure are the model estimates of Schubert et al. (1991), Tarasick and Shepherd (1992a, b), and Walterscheid and Schubert (1995). We also plot observed $\eta$ and $\Phi$ values against their observed period in Fig. 2a1 and b1. In general, we note that the parameter $\eta$ increases with wave period. It is evident that the observed $\eta$ and $\Phi$ values in our study show a large spread in their distribution as compared to the model values. A similar spread in the distribution of observed values of $\eta$ (Fig. 2a) from 1.03 to 7.85 has also been observed by other investigators (e.g., Takahashi et al., 1992). It may be noted that the values of $\eta$ for the $\mathrm{OH}$ data in our study lie somewhere between the model estimates and the values observed by other investigators. Also noteworthy in this figure is that our $\eta$ values are closer to the model values reported by Tarasick and Shepherd (1992a) for the waves with horizontal wavelength of $500 \mathrm{~km}$. The observed phase " $\Phi$ " values, on the other hand, show significantly larger deviations from this model for 2010, while for 2011 agreement seems to be better. We note that our measurements of $\Phi$ matches somewhat with those reported by Viereck and Deehr (1989), while large differences with other published results can be easily noted. The variation in $\Phi$ values with respect to the wave periodicity obtained in the year 2010 clearly shows that most of the time we observe values to be higher than those obtained by different models.

Of the importance is that Reisin and Scheer (2001) found $\eta$ values of $3.47 \pm 0.07$ corresponding to the wave periods between $1000 \mathrm{~s}$ and $3 \mathrm{~h}$. Our observed values of $\eta$ (arithmetic mean, $4.4 \pm 1$ for the year 2010 and $5.7 \pm 1.7$ for 2011) for $\mathrm{OH}$ measurements agree well with this report. In another study based on long-term observations with a spectral airglow temperature imager (SATI) from a mid-latitude station, Lopez-Gonzalez et al. (2005) reported a mean value of $\eta$ of approximately $\sim 8.6$ for the $\mathrm{OH}$ measurements with a larger variability than our observations show. In another re- 


\section{6-27 January 2011; Kolhapur}
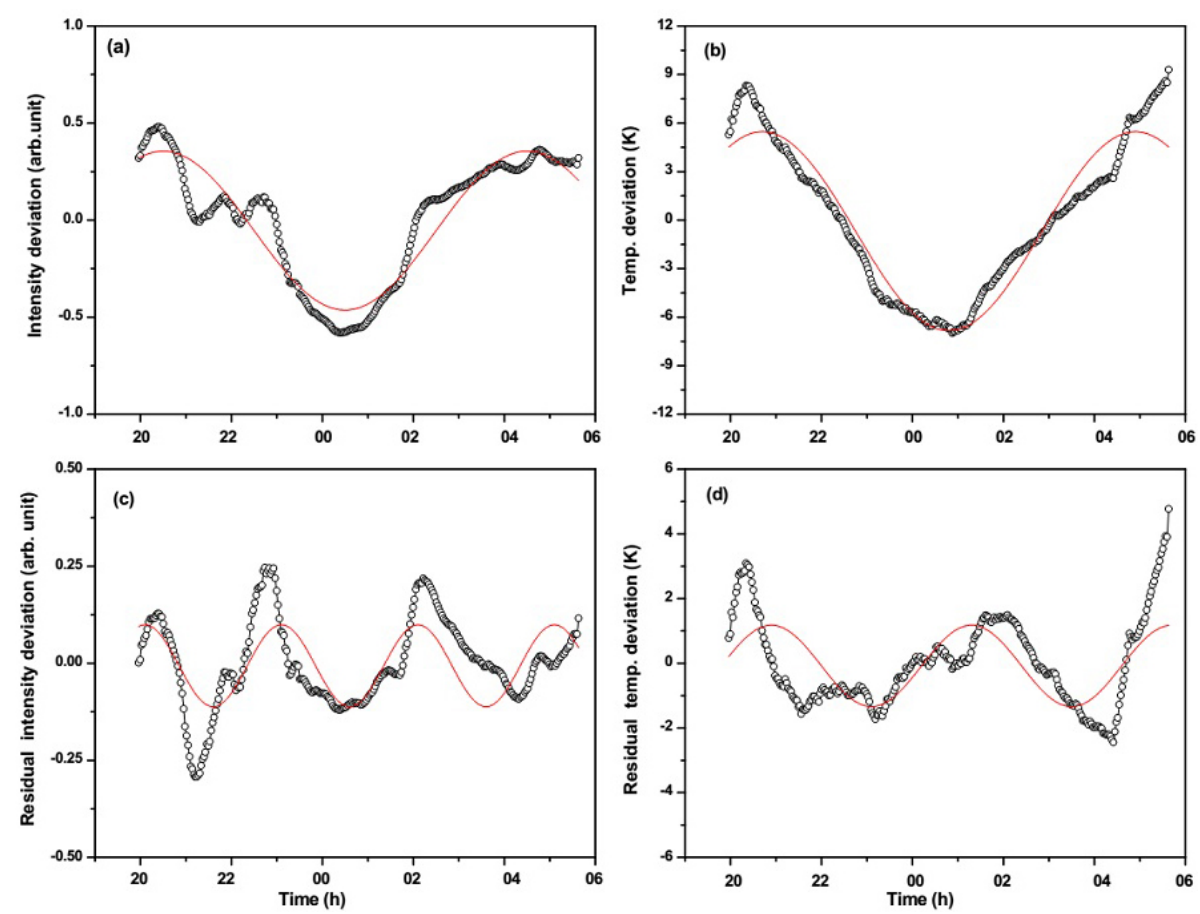

Figure 1. Nocturnal variability in the mesospheric OH emissions on 26-27 January 2011. The upper panels represent the mean deviations in (a) intensity and (b) temperature data. Bottom panels represent (c) intensity and (d) temperature residuals. Solid red curves in each plot show the result of the simple best-fit cosine model.

port, Guharay et al. (2008) found that, for wave periods ranging from 6 to $13 \mathrm{~h}$, values of $\eta$ were between 1.7 and 5.4, while the phase varied from -13 to $-90^{\circ}$. Similarly, Aushev et al. (2008) reported amplitudes of the Krassovsky parameter for wave periods ranging from 2.2 to $4.7 \mathrm{~h}$ to vary from 2.4 to 3.6 , while the phase values were found to lie within -63 and $-121^{\circ}$. It is noteworthy that our derived values broadly agree with Guharay et al. (2008, 2009), Reisin and Scheer (2001, 2004), and Viereck and Deehr (1989), while they are somewhat different from the values reported by Lopez-Gonzalez et al. (2005), which may be due to the fact that their observations corresponded to higher latitude than ours. It also remains to be seen how that would be reflected in the Krassovsky parameters when mesopause altitude itself changes from low to high latitudes.

The results of ( $\eta$ and $\Phi)$ shown in Fig. 2 emphasize that there are significant differences in the Krassovsky parameters derived from one study to another. This we suspect to be caused by the variations in the altitudinal profile of oxygen and its effect on the $\eta$ through the complex $\mathrm{OH}$ chemistry (Walterscheid et al., 1994). Another possibility over low latitudes was discussed by Makhlouf et al. (1995), who suggested that the quenching was caused by the perturbed molecules during their transitions from several vibrational levels. Winds also affect the $\mathrm{OH}$ response to gravity waves and therefore they will also contribute to the spread of values seen between the various observation studies (e.g., Sonnemann and Grygalashvyly, 2003).

Note that our observations as well as simulations show the phase $\Phi$ for $\mathrm{OH}$ to be a negative value, indicating upwardpropagating waves (see Tarasick and Shepherd, 1992a, b). In general we note that our $\Phi$ values, although they are on some occasions closer to Viereck and Deehr (1989) observations, show deviations from other investigators and are larger than the model values on most occasions. Differences in theory and observation may be due to the horizontal wavelength assumed in the model and/or the Prandtl number (ratio of kinematic viscosity to thermal diffusivity) assumed. The Prandtl number is important in theoretical calculations and modeling, especially when in terms of dissipating waves owing to molecular viscosity and thermal diffusivity while they propagate in the atmosphere (Hickey, 1988). An error in the Prandtl number assumption will affect the derived wave parameters $\left(\lambda_{z}, \eta\right.$, etc.), which may in turn result in misleading results. In this regard, Makhlouf et al. (1995) studied the variations in the $\eta$ values by modifying the model proposed by Hines and using a photochemical dynamical model; however, they were still unable to explain the appearance of the negative phases appropriately. Hines and Tarasick (1987) found a wide range of $\eta$ variability, a result supported by our measurements. Further, Hines and Tarasick (1997) subsequently discussed the necessary correction for thin and 

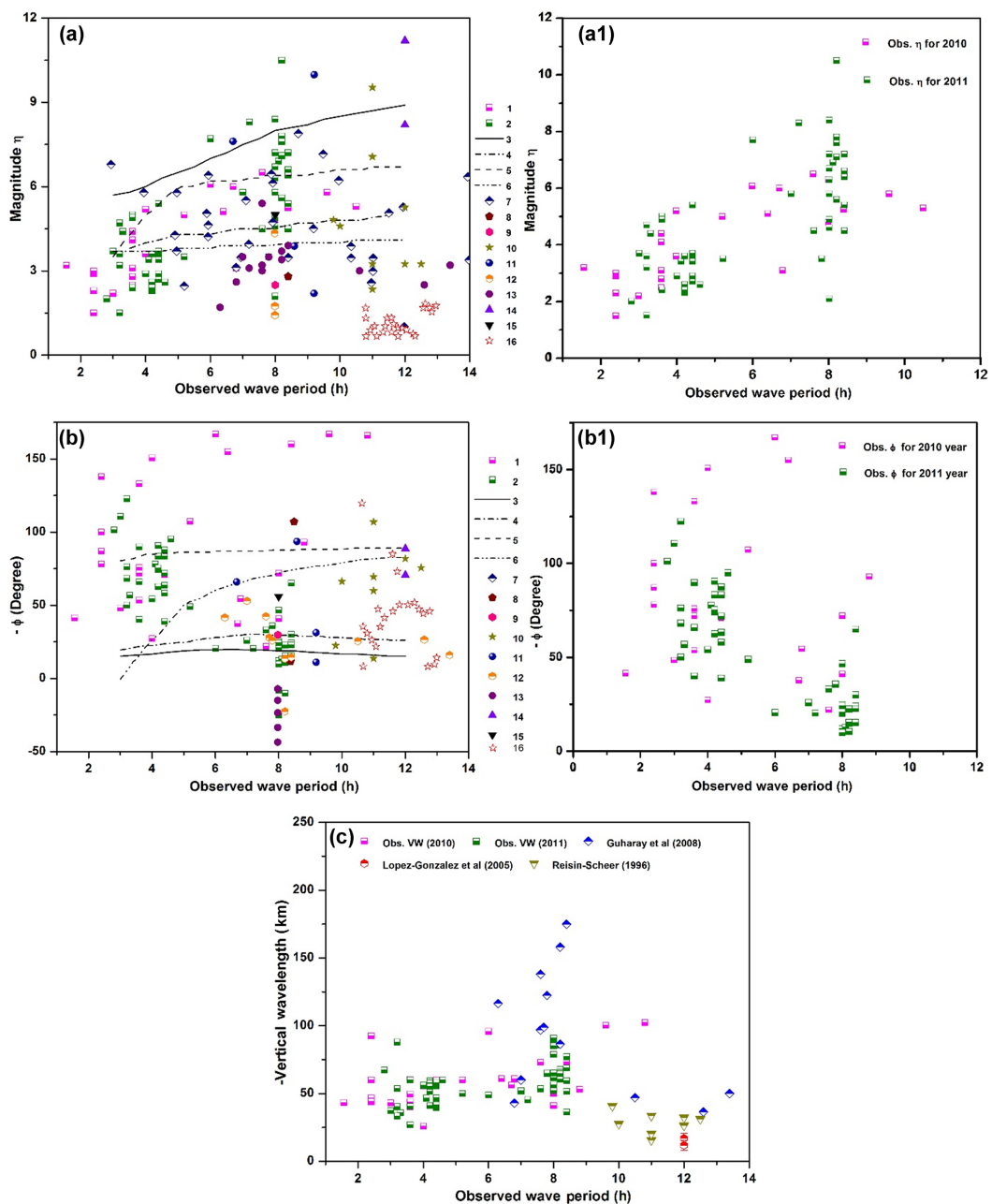

Figure 2. (a) Distribution of Krassovsky parameter " $\eta$ ", reported by investigators (list not exhaustive). The $x$ axis shows the wave periodicity and the $y$ axis is for amplitude of Krassovsky parameters $(\eta)$. The legends in the figure are as follows: (1) (for year 2010) and (2) (for year 2011) - present study; (3) Schubert et al. $500 \mathrm{~km}$; (4) Schubert et al. $1000 \mathrm{~km}$; (5) Tarasick and Shepherd 500 km; (6) Tarasick and Shepherd 1000 km; (7) Takahashi et al. (1992); (8) Oznovich et al. (1995); (9) Drob et al. (1996); (10) Reisin and Scheer (1996); (11) Taylor et al. (2001); (12) Guharay et al. (2008); (13) Walterscheid and Schubert (1995); (14) Lopez-Gonzalez et al. (2005); (15) Oznovich et al. (1997); and (16) Viereck and Deehr (1989). (a1) Observed values of $\eta$ versus wave period over Kolhapur alone. (b) Distribution of phase values of Krassovsky parameter " $\Phi$ ”, reported by investigators (list not exhaustive) (1) (for year 2010) and (2) (for year 2011) - present study; (3) Schubert et al. 500 km; (4) Schubert et al. 1000 km; (5) Tarasick and Shepherd 500 km; (6) Tarasick and Shepherd 1000 km; (7) Viereck and Deehr (1989); (8) Oznovich et al. (1995); (9) Drob et al. (1996); (10) Reisin and Scheer (1996); (11) Taylor et al. (2001); (12) Guharay et al. (2008); (13) Walterscheid and Schubert (1995); (14) Lopez-Gonzalez et al. (2005); (15) Oznovich et al. (1997); and (16) Viereck and Deehr (1989). (b1) Observed values of $\Phi$ verses wave period over Kolhapur alone. (c) Deduced vertical wavelength (VW) for both the short- and long-period wave as a function of wave periodicity compared to other published results.

thick layer approximations for the calculation of $\eta$ from airglow emissions due to gravity wave interaction. They also pointed out that $\mathrm{OH}$ emission intensity, which affects the derived $\eta$ values, does not depend on the oxygen profile and other minor species, which contradicts the theory of Walterscheid et al. (1994) and Schubert et al. (1991). The calculated vertical wavelengths (VWs) for all the nights of the observation are shown in Fig. $2 \mathrm{c}$ as pink half-filled squares indicating the estimates for the year 2010 and green halffilled squares for the year 2011. Large differences exist from one night to another. The VW has a large variability ranging from -41 to $-102 \mathrm{~km} \mathrm{(2010)}$ and -36.2 to $-140 \mathrm{~km}$ (2011) for long-period waves, and -26 to $-92.4 \mathrm{~km}$ and -24 to $-88 \mathrm{~km}$ for short-period waves of years 2010 and 2011 , respectively. In 2010 (and 2011), the mean VW values for long- and short-period waves are calculated to be $-60.2 \pm 20$ $(-77.2 \pm 40 \mathrm{~km})$ and $-42.8 \pm 15 \mathrm{~km}(-59.2 \pm 30 \mathrm{~km})$, respectively. Further, unlike the clear dependency on the wave period noted in the Krassovsky parameters ( $\eta$ and $\Phi$ ) no clear trend is noted in the calculated VW. We also plot the values 
reported by Reisin and Scheer (1996) and Lopez-Gonzalez et al. (2005) for a comparison. It is noteworthy that, for all days, the VW values for the long-period wave are higher than those of short-period waves. We also observed that VW values calculated for the year 2011 are larger than year 2010 calculated values. We note that the values reported by Reisin and Scheer (1996) are approximately $-30 \mathrm{~km}$ with about $40 \mathrm{~km}$ variability. Our values are in good agreement with them. However, Lopez-Gonzalez et al. (2005) observed VW values to be approximately $-10 \mathrm{~km}$ deduced from their $\mathrm{OH}$ observations, which do not agree with our values. Further, Ghodpage et al. (2012) analyzed the long-term nocturnal data of 2004-2007 and also observed that the VW lies between 28.6 and $163 \mathrm{~km}$. Recently, Ghodpage et al. (2013) studied the simultaneous mesospheric gravity wave measurements in the $\mathrm{OH}$ emission from Gadanki and Kolhapur, inferring mean VW values varying from -26 to $-60 \mathrm{~km}$ for the Kolhapur observations. Takahashi et al. (1990) reported vertical wavelengths varying from 20 to $80 \mathrm{~km}$, which is in agreement with our values.

\section{Comparison with the full-wave model results}

Wave simulations were performed using the full-wave model (FWM) for which the representative inputs were taken for the duration of observations reported in Sect. 3. The observations were conducted over a period of approximately 1 month spanning from 8 February to 13 March, and accordingly we used the middle date of this observation period (25 February) in the MSIS model to represent the mean state. The latitude used was $16.8^{\circ} \mathrm{N}$, and the local time was midnight. Because the speed and direction of wave propagation were not determined from the observations, several simulations were performed for each wave period in which the direction of propagation (eastward, northward, and westward propagation) and the phase speed $\left(50,100\right.$, and $\left.150 \mathrm{~m} \mathrm{~s}^{-1}\right)$ were varied. Note that the mean winds (not shown) in these simulations were derived from the Horizontal Wind Model (HWM) using the same input parameters as used for the MSIS model. The derived meridional winds (not shown) are far smaller than the zonal winds for the conditions considered here, and so while results for eastward and westward propagation differed quite markedly, those for northward and southward propagation did not. Hence we considered only a single direction (northward) for meridional propagation.

We also performed a tidal simulation using an equivalent gravity wave model (Lindzen, 1970; Richmond, 1975), as implemented in an earlier study (Walterscheid and Hickey, 2001). The horizontal wavelength and the Coriolis parameter are adjusted to give maximal correspondence with a given tidal mode. Here, we performed calculations for the terdiurnal $(3,3),(3,4),(3,5)$, and $(3,6)$ modes using parameters provided by Richmond (1975). The simplifications in- herent in this approach are discussed by Walterscheid and Hickey (2001).

Comparisons between the full-wave model results for $\eta$, $\Phi$, and $\lambda_{\mathrm{z}}$ and the values inferred from the observations are shown in Fig. 3a, b, and c, respectively. In Fig. 3a we compare the observed values of $\eta$ for 2010 and 2011. The observed values of $\eta$ are represented as pink and green lower half-filled squares for 2010 and 2011, respectively. In Fig. 3a we note that, at a few of the longer wave periods, the observed values of $\eta$ are in good agreement with the full-wave model results. For short-period waves the values of $\eta$ inferred from the observations appear to be bounded by the model values for waves with horizontal phase velocities of 50 and $100 \mathrm{~m} \mathrm{~s}^{-1}$, respectively. For example, for $3.6 \mathrm{~h}$ wave periods, the average of the values of $\eta$ inferred from the observations is 3.7, while the full-wave model values lie between about 0.5 (for the $100 \mathrm{~m} \mathrm{~s}^{-1}$ wave) and 7 (for the $50 \mathrm{~m} \mathrm{~s}^{-1}$, eastwardpropagating wave). For the $8 \mathrm{~h}$ wave periods, the average of the values of $\eta$ inferred from the observations is 5.7, which is bounded by the full-wave model estimates for waves having a horizontal phase velocity of $50 \mathrm{~m} \mathrm{~s}^{-1}$ and different propagation directions.

Overall, we note that the comparison between the observed $\eta$ values and the modeled values can be explained by gravity waves whose horizontal phase velocities range from 50 to $100 \mathrm{~m} \mathrm{~s}^{-1}$. In this regard, an earlier investigation by Pragati et al. (2010) observed gravity wave horizontal phase speeds (for periods 5 to $17 \mathrm{~min}$ ) varying between 10 and $48 \mathrm{~m} \mathrm{~s}^{-1}$. The propagation directions were reported to be preferentially towards the north. More recently, Taori et al. (2013) studied mesospheric gravity wave activity in the $\mathrm{OH}$ and OI $558 \mathrm{~nm}$ emissions from Gadanki. They observed that the gravity waves were moving in the northwest direction. The average phase velocity of the ripple-type waves was found to be $23.5 \mathrm{~m} \mathrm{~s}^{-1}$. The other, band-type waves, with horizontal scales of about $40 \mathrm{~km}$, were found to be propagating from south to north with an estimated phase speed of $90 \mathrm{~m} \mathrm{~s}^{-1}$.

The vertical wavelengths $\left(\lambda_{z}\right)$ calculated using the observed values of $\eta$ and $\Phi$ differ significantly from the fullwave model estimate for waves with phase velocities below $100 \mathrm{~m} \mathrm{~s}^{-1}$. More typically, a comparison between those values inferred from the observations and those derived from the model tend to agree for phase velocities in the $100-150 \mathrm{~m} \mathrm{~s}^{-1}$ range. However, it should be noted that vertical wavelengths inferred from the observations are based on the use of the inferred Krassovsky's ratio, $\eta$, in Eq. (2). Note that the errors in the determination of the phase $(\Phi)$ of $\eta$ may lead to significant errors (proportional to $\cot \Phi$ ) in the determination of $\lambda_{z}$, especially as $\Phi$ approaches $\pm 180^{\circ}$.

The differences noted in the observed and modeled estimates of Krassovsky ratio magnitudes $\eta$ and phase $(\Phi)$ may be associated with the limitation arising due to dynamics as well as the measurements. In terms of measurements limitation, the parameters achieved with the best-fit method may have leaked contribution from other wave components, 
Table 1. Comparisons of deduced wave parameters in years 2010 and 2011 with the multivariate ENSO index (MEI) and OH altitudes. The observed quantities are the mean for their representative wave periods. (Abbreviations under MEI are for 3-month periods, e.g., JFM January, February, and March.)

\begin{tabular}{|c|c|c|c|c|c|c|c|c|c|c|c|c|}
\hline \multirow[t]{2}{*}{ Year } & \multicolumn{2}{|c|}{$\begin{array}{c}\text { Mean } \eta \\
( \pm \text { errors })\end{array}$} & \multicolumn{2}{|c|}{$\begin{array}{c}\operatorname{Mean}(\Phi) \\
\left({ }^{\circ}\right)\end{array}$} & \multicolumn{2}{|c|}{$\begin{array}{l}\text { Mean }(\mathrm{VW}) \\
(\mathrm{km})\end{array}$} & \multirow[t]{2}{*}{$\begin{array}{r}\text { OH altitude } \\
(\mathrm{km})\end{array}$} & \multicolumn{5}{|c|}{ MEI } \\
\hline & $\begin{array}{r}\text { Long } \\
\text { wave } \\
\text { period }\end{array}$ & $\begin{array}{r}\text { Short } \\
\text { wave } \\
\text { period }\end{array}$ & $\begin{array}{r}\text { Long } \\
\text { wave } \\
\text { period }\end{array}$ & $\begin{array}{r}\text { Short } \\
\text { wave } \\
\text { period }\end{array}$ & $\begin{array}{r}\text { Long } \\
\text { wave } \\
\text { period }\end{array}$ & $\begin{array}{r}\text { Short } \\
\text { wave } \\
\text { period }\end{array}$ & & JFM & FMA & MAM & SON & OND \\
\hline 2010 & $4.4 \pm 1$ & $2.3 \pm 0.9$ & $90.6 \pm 40$ & $70.4 \pm 45$ & $60.2 \pm 20$ & $42.8 \pm 15$ & $\begin{array}{r}82 \text { to } 85.1 \mathrm{~km} \\
\text { during } \\
\text { Feb-Apr }\end{array}$ & 1.1 & 0.8 & 0.5 & -1.4 & -1.3 \\
\hline 2011 & $5.7 \pm 1.7$ & $2.7 \pm 0.6$ & $33.8 \pm 40$ & $64.4 \pm 40$ & $77.6 \pm 40$ & $59.2 \pm 30$ & $\begin{array}{r}85.1 \text { to } 86 \mathrm{~km} \\
\text { during } \\
\text { Feb-Apr }\end{array}$ & -1.1 & -0.8 & -0.6 & -0.9 & -0.9 \\
\hline
\end{tabular}

which may be dynamically varying within a wave period. In terms of dynamics, that full-wave model uses climatological density (both major gas and minor airglow-related species) and wind profiles, which will introduce uncertainties. This point has been previously elaborated by Walterscheid et al. (1994) with respect to the effect of a change in the $[\Phi]$ profile on the $\mathrm{OH}$ response to wave motions.

It is interesting to note that the arithmetic mean values of $|\eta|$ for the years 2010 and 2011 were 4.4 and 5.7, respectively. When we look at each $|\eta|$ value from one wave period range to other, the difference is found to be more than $30 \%$, which is well above the maximum errors in the estimation. One may further argue that this difference may not be significant. For this, we looked at the mode of the values for periods ranges $1-4,4-6,6-8$, and $8-10 \mathrm{~h}$. We found that in each case in the year 2011 mode values are larger than the year 2010. The differences noted in the magnitude of the observed Krassovsky ratio $\eta$ between 2010 and 2011 may be associated with variations in the height and shape of the undisturbed $\mathrm{OH}$ emission profile. We use the SABER data to investigate this aspect. To check whether there was a difference in the $\mathrm{OH}$ emission layer structure, we selected the nighttime $\mathrm{OH}$ emission profile for a grid encompassing 10 to $20^{\circ} \mathrm{N}$ and 70 to $90^{\circ} \mathrm{E}$ during the months of February, March, and April of the years 2010 and 2011. We have selected the February to March period because the optical airglow data used in this study were acquired primarily during these months. The monthly mean values of $\mathrm{OH}$ emission rates are shown in Fig. 4. The solid curves correspond to 2010 data, while the dashed curves correspond to 2011 data. We note that the peaks of $\mathrm{OH}$ emission layer during February, March and April of 2010 occurred at 84.2, 82.8, and $85.1 \mathrm{~km}$ altitude, respectively, while the corresponding peaks for 2011 were found to occur at $85.8,85.6$, and $85.2 \mathrm{~km}$ altitude. This suggests that the peak of the emission layer occurred at a somewhat lower altitude in 2010 compared to 2011. Also, the emission rates during February and March were found to be higher in 2010. It is important to note that, in an earlier study, Ghodpage et al. (2013) compared the Krassovsky ratios at two different latitudes, Gadanki $\left(13.5^{\circ} \mathrm{N}, 79.2^{\circ} \mathrm{E}\right)$ and Kolhapur $\left(16.8^{\circ} \mathrm{N}, 74.2^{\circ} \mathrm{E}\right)$, and noted a lower $\mathrm{OH}$ emission layer peak over Kolhapur as well as larger estimated $\eta$ values over Kolhapur. In the present case, instead of the location, it is the difference in the measurement year where the peak emission altitudes of the $\mathrm{OH}$ emission layer are somewhat different. As the peak emission layer arises due to the chemical reactions involving odd oxygen, it is proposed that chemical composition was different from 2010 to 2011. Therefore, modified $\mathrm{OH}$ emission rates may be responsible for the observed differences in the Krassovsky parameters. A further question that arises here is why the peaks should be different from one year to the other. As these months are pre-monsoon, when a large-scale oscillation, namely El Niño-Southern Oscillation (ENSO), sweeps through the South Asian continent, we looked at ENSO strength based on the multivariate ENSO index (MEI). This index is shown in Table 1, where it is noteworthy that the MEI for 2010 (January to May) is of opposite sign to that for the corresponding months in 2011 . We postulate that these large-scale processes have a profound impact on the observed wave energetics and dynamics at mesospheric altitudes. Large-scale processes induced the wave oscillations associated with ENSO. ENSO generates a spectrum of waves which are of planetary scales. These are expected to generate a secular variation in temperature and density structure throughout the atmosphere. A difference in ENSO suggests that these forcings are different in the two years (2010 and 2011). At present, we do not know through which process ENSO may have implications in the observed wave characteristics. However, we believe that further investigation is required in order to confirm whether or not any such associations really do exist. 

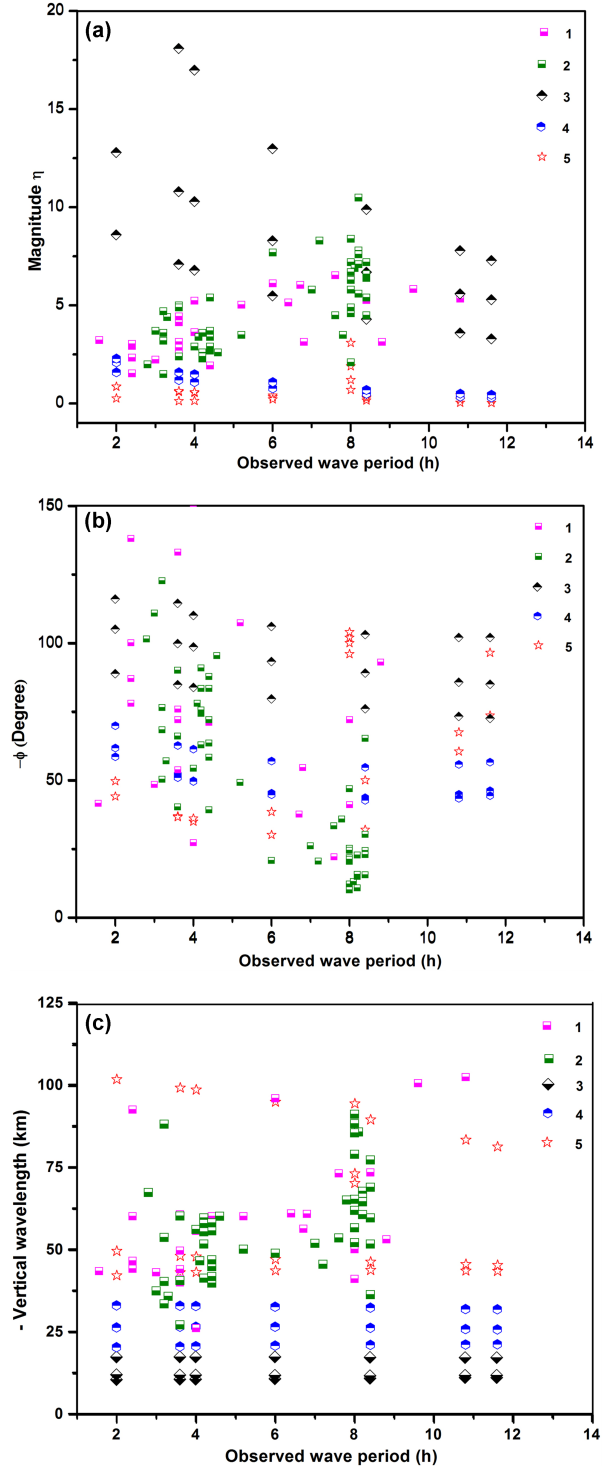

Figure 3. (a) Comparison with $\eta$ calculated by observation of both years and full-wave model simulation with their respective wave period. Pink and green lower half-filled squares show the year 2010 and $2011 \eta$ observations: (1) and (2) - present study $\eta$; (3) FWM simulation of $\eta$ for $50 \mathrm{~m} \mathrm{~s}^{-1}$ horizontal phase velocity; (4) FWM simulation of $\eta$ for $100 \mathrm{~m} \mathrm{~s}^{-1}$ horizontal phase velocity; and (5) FWM simulation of $\eta$ for $150 \mathrm{~m} \mathrm{~s}^{-1}$ horizontal phase velocity). (b) Similar to (a) but for phase values for both the short- and longperiod wave. (c) Similar to (a) but for deduced vertical wavelength (VW).

\section{Conclusions}

We report the Krassovsky parameters for the observed gravity waves from Kolhapur $\left(16.8^{\circ} \mathrm{N}, 74.2^{\circ} \mathrm{E}\right)$ and their comparison with the full-wave model.

1. The observed values of Krassovsky parameters in our study show a large spread in their distribution as com-

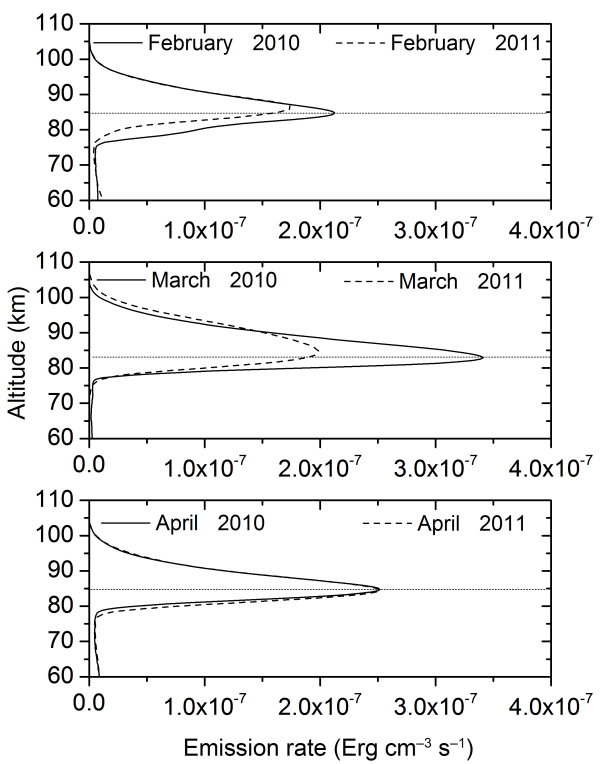

Figure 4. The monthly (February, March, and April) mean $\mathrm{OH}$ emission rate profiles from SABER for the years 2010 (solid lines) and 2011 (dashed lines).

pared to the model values (shown in Fig. 2a). A similar spread in the distribution has also been reported by other investigators. We have also observed that the magnitude of $\eta$ values is larger in the year 2011 than 2010 .

2. The values of $\eta$ for the $\mathrm{OH}$ data in our study lie between the model estimates and the values reported in other published results. However, the phase values are more than the model values on most occasions. We note that our $\Phi$ measurements match with those reported by Viereck and Deehr (1989), while they show large differences with the values in other reports.

3. Observed vertical wavelength (VW) values broadly agree with the range reported by other investigators and are found to vary from -26 to $-140 \mathrm{~km}$. We also noted that VW values calculated for the year 2011 are larger than year 2010 calculated values. Most of the waves are propagating upward.

4. Comparisons of observed $\eta$ and $\Phi$ values agree fairly well with the full-wave model results for waves with 50 and $100 \mathrm{~m} \mathrm{~s}^{-1}$ horizontal phase velocities. Vertical wavelengths tend to agree for waves with 100 and $150 \mathrm{~m} \mathrm{~s}^{-1}$ horizontal phase velocities, except for the longest period waves for which vertical wavelength cannot be reliably inferred from the observations.

\section{Data availability}

The database used in the present study are limited in terms of the length (time and duration) and locations. Based 
on the above conclusions we emphasize that more rigorous studies using coordinated observations and modeling are required to uncover the physics occurring in the upper mesosphere. These database are available upon request to: alok.taori@gmail.com.

Acknowledgements. This work was carried out with support from a research grant funded by the Ministry of Science and Technology and Department of Space, Govt. of India. R. N. Ghodpage thanks the director of the Indian Institute of Geomagnetism (IIG), Navi Mumbai, for encouragement to carry out this work. The night airglow observations at Kolhapur were carried out as part of the scientific collaboration program (MoU) between the IIG, Navi Mumbai, and Shivaji University, Kolhapur. M. P. Hickey acknowledges the support of NSF grant AGS-1001074.

Edited by: J. Kuttippurath

\section{References}

Aushev, V. M., Lyahov, V. V., Lopez-Gonzalez, M. J., Shepherd, M. G., and Dryna, E. A.: Solar eclipse of the 29 March 2006: results of the optical measurements by MORTI over Almaty $\left(43.03^{\circ} \mathrm{N}\right.$, 76.58 E), J. Atmos. Sol. Terr. Phys., 70, 1088-1101, 2008.

Bruce, G. H., Peaceman, D. W., Rachford Jr., H. H., and Rice, J. D.: Calculations of unsteady-state gas flow through porous media, Petrol. Trans. AIME, 198, 79-92, 1953.

Bittner, M., Offermann, D., and Graef, H. H.: Mesopause temperature variability above a midlatitude station in Europe, J. Geophys. Res., 105, 2045-2058, 2000.

Drob, D. P.: Ground-based optical detection of atmospheric waves in the upper mesosphere and lower thermosphere, $\mathrm{Ph}$. D. Thesis, University of Michigan, Ann Arbor, MI, 1996.

Ghodpage, R. N., Singh, D., Singh, R. P., Mukherjee, G. K., Vohat, P., and Singh, A. K.: Tidal and gravity waves study from the airglow measurements at Kolhapur (India), J. Earth Syst. Sci., 121, $1511-1525,2012$.

Ghodpage, R. N., Taori, A., Patil, P. T., and Gurubaran, S.: Simultaneous mesospheric gravity wave measurements in $\mathrm{OH}$ night airglow emission from Gadanki and Kolhapur - Indian low latitudes, Curr. Sci. India, 104, 98-105, 2013.

Ghodpage, R. N., Taori, A., Patil, P. T., Gurubaran, S., Sharma, A. K., Nikte, S., and Nade, D.: Airglow Measurements of Gravity Wave Propagation and Damping over Kolhapur $\left(16.8^{\circ} \mathrm{N}\right.$, 74.2 ${ }^{\circ}$ E), Int. J. Geophys., 2014, 1-9, 2014.

Greet, P. A., French, W. J. R., Burns, G B., Williams, P. F. B., Lowe, R. P., and Finlayson, K.: OH (6-2) spectra and rotational temperature measurements at Davis, Antarctica, Ann. Geophys., 16, 77-89, 1998.

Guharay, A., Taori, A., and Taylor, M.: Summer-time nocturnal wave characteristics in mesospheric $\mathrm{OH}$ and $\mathrm{O}_{2}$ airglow emissions, Earth Planets Space, 60, 973-979, 2008.

Guharay, A., Taori, A., Bhattacharjee, B., Pant, P., Pande, P., and Pandey, K.: First ground-based mesospheric measurements from central Himalayas, Curr. Sci. India, 97, 664-669, 2009.

Hecht, J. H., Walterscheid, R. L., Christensen, A. B., and Pranke, J. B.: Observations of wave-driven fluctuations of $\mathrm{OH}$ nightglow emission bfrom Sondre Stromfjord, Greenland, J. Geophys. Res., 92, 6091-6099, 1987.

Hedin, A. E.: Extension of the MSIS thermosphere model into the middle and lower atmosphere, J. Geophys. Res., 96, 1159-1172, 1991.

Hickey, M. P.: Effects of eddy viscosity and thermal conduction and coriolis force in the dynamics of gravity wave driven fluctuations in the $\mathrm{OH}$ nightglow, J. Geophys. Res., 93, 4077, doi:10.1029/JA093iA05p04077, 1988.

Hickey, M. P. and Cole, K. D.: A quartic dispersion equation for internal gravity waves in the thermosphere, J. Atmos. Terr. Phys., 49, 889-899, 1987.

Hickey, M. P. and Yu, Y.: A full-wave investigation of the use of a "cancellation factor" in gravity wave-OH airglow interaction studies, J. Geophys. Res., 110, A01301, doi:10.1029/2003JA010372, 2005.

Hickey, M. P., Schubert, G., and Walterscheid, R. L.: Gravity wavedriven fluctuations in the $\mathrm{O}_{2}$ atmospheric (0-1) nightglow from an extended, dissipative emission region, J. Geophys. Res., 98, 717-730, 1993.

Hickey, M. P., Walterscheid, R. L., Taylor, M. J., Ward, W., Schubert, G., Zhou, Q., Garcia, F., Kelley, M. C., and Shepherd G. G.: Numerical simulations of gravity waves imaged over Arecibo during the 10-day January 1993 campaign, J. Geophys. Res., 102, 11475-11489, 1997.

Hickey, M. P., Taylor, M. J., Gardner, C. S., and Gibbons, C. R.: Full-wave modeling of small-scale gravity waves using Airborne Lidar and Observations of the Hawaiian Airglow (ALOHA-93) $\mathrm{O}(1 \mathrm{~S})$ images and coincident $\mathrm{Na}$ wind/ temperature lidar measurements, J. Geophys. Res., 103, 6439-6453, 1998.

Hines, C. O.: A fundamental theorem of airglow fluctuations induced by gravity waves, J. Atmos. Sol. Terr. Phys., 59, 319-326, 1997.

Hines, C. O. and Tarasick, D. W.: On the detection and utilization of gravity waves in airglow studies, Planet Space Sci., 35, 851-866, 1987.

Hines, C. O. and Tarasick, D. W.: Layer truncation and the Eulerian/ Lagrangian duality in the theory of airglow fluctuations induced by gravity waves, J. Atmos. Sol. Terr. Phys., 59, 327-334, 1997.

Krassovsky, V. I.: Infrasonic variation of $\mathrm{OH}$ emission in the upper atmosphere, Ann. Geophys., 28, 739-746, 1972.

Lindzen, R. S.: Internal gravity waves in atmospheres with realistic dissipation and temperature, part I: Mathematical development and propagation of waves into the thermosphere, Geophys. Fluid Dyn., 1, 303-355, 1970.

Lindzen, R. S. and Kuo, H. L.: A reliable method for the numerical integration of a large class of ordinary and partial differential equations, Mon. Weather Rev., 97, 732-734, 1969.

Liu, A. Z. and Swenson, G. R.: A modeling study of $\mathrm{O}_{2}$ and $\mathrm{OH}$ airglow perturbations induced by atmospheric gravity waves, J. Geophys. Res, 108, D44151, doi:10.1029/2002JD002474, 2003.

Lopez-Gonzalez, M. J., Rodríguez, E., Shepherd, G. G., Sargoytchev, S., Shepherd, M. G., Aushev, V. M., Brown, S., GarciaComas, M., and Wiens, R. H.: Tidal variations of $\mathrm{O}_{2}$ Atmospheric and $\mathrm{OH}(6-2)$ airglow and temperature at mid-latitude from SATI observations, Ann. Geophys., 23, 3579-3590, 2005.

Makhlouf, U. B., Picard, R. H., and Winick, J. R.: Photochemicaldynamical modeling of the measured response of airglow to grav- 
ity waves, 1: basic model for OH airglow, J. Geophys. Res., 100, 11289-11311, 1995.

Mies, F. H.: Calculated vibrational transitions probabilities of $\mathrm{OH}$ $\left(\mathrm{X}^{2} \pi\right)$, J. Mol. Spectrosc., 53, 150-188, 1974.

Meinel, A. B.: OH Emission bands in the spectrum of the night sky I, Astrophys. J., 111, 555-564, 1950.

Meriwether, J. W.: High latitude airglow observations of correlated short term fluctuations in the hydroxyl Meinel 8-3 band intensity and rotational temperature, Planet Space Sci., 23, 1211-1221, 1975.

Oznovich, I., McEwen, D. J., and Sivjee, G. G.: Temperature and airglow brightness oscillations in the polar mesosphere and lower thermosphere, Planet Space Sci., 43, 1121-1130, 1995.

Oznovich, I., Walterscheid, R. L., Sivjee, G. G., and McEwen, D. J.: On Krassovsky's ratio for ter-diurnal hydroxyl oscillations in the winter polar mesopause, Planet Space Sci., 45, 385-394, 1997.

Pragati, R. S., Parihar, N., Ghodpage, R., and Mukherjee, G. K.: Characteristics of gravity waves in the upper mesosphere region observed by $\mathrm{OH}$ airglow imaging, Curr. Sci. India, 98, 392-397, 2010

Reisin, E. R. and Scheer, J.: Characteristics of atmospheric waves in the tidal period range derived from zenith observations of $\mathrm{O}_{2}(0$ 1) Atmospheric and $\mathrm{OH}$ (6-2) airglow at lower mid latitudes, J. Geophys. Res., 101, 21223-21232, 1996.

Reisin, E. R. and Scheer, J.: Vertical propagation of gravity waves determined from zenith observations of airglow, Adv. Space Res., 27, 1743-1748, 2001.

Richmond, A. D.: Energy relations of atmospheric tides and their significance to approximate methods of solution for tides with dissipative forces, J. Atmos. Sci., 32, 980-987, 1975.

Schubert, G., Walterscheid, R. L., and Hickey, M. P.: Gravity wavedriven fluctuations in $\mathrm{OH}$ nightglow from an extended, dissipative emission region, J. Geophys. Res., 96, 13869-13880, 1991.

Schubert, G., Hickey, M. P., and Walterscheid, R. L.: Heating of Jupiter's thermosphere by the dissipation of upward propagating acoustic waves, Icarus, 163, 398-413, 2003.

Sivjee, G. G. and Hamwey, R. M.: Temperature and chemistry of the polar mesopause OH, J. Geophys. Res., 92, 4663-4672, 1987.

Sonnemann, G. and Grygalashvyly, M.: The zonal wind effect on the photochemistry within the mesosphere/menopause region, Adv. Space Res., 32, 719-724, 2003.

Takahashi, H., Sahai, Y., and Teixeira, N. R.: Airglow intensity and temperature response to atmospheric wave propagation in the mesopause region, Adv. Space Res. 10, 77-81, 1990.

Takahashi, H., Sahai, Y., Batista, P. P., and Clemesha, B. R.: Atmospheric gravity wave effect on the airglow $\mathrm{O}_{2}(0-1)$ and $\mathrm{OH}(9-4)$ band intensity and temperature variations observed from a low latitude station, Adv. Space Res., 12, 131-134, 1992.

Takahashi, H., Batista, P. P., Buriti, R. A., Gobbi, D., Nakamura, T., Tsunda, T., and Fukao, S.: Simultaneous measurements of airglow $\mathrm{OH}$ emission and meteor wind by a scanning photometer and the MU radar, J. Atmos. Sol. Terr. Phys., 60, 1649-1668, 1998.
Taori, A. and Taylor, M. J.: Characteristics of wave induced oscillations in mesospheric $\mathrm{O}_{2}$ emission intensity and temperatures, Geophys. Res. Lett., 33, L01813, doi:10.1029/2005GL024442, 2006.

Taori, A., Taylor, M. J., and Franke, S.: Terdiurnal wave signatures in the upper mesospheric temperature and their association with the wind fields at low latitudes $\left(20^{\circ} \mathrm{N}\right)$, J. Geophys. Res., 110 , D09S06, doi:10.1029/2004JD004564, 2005.

Taori, A., Jayaraman, A., and Kamalakar, V.: Imaging of mesosphere-thermosphere airglow emissions over Gadanki $\left(13.5^{\circ} \mathrm{N}, 79.2^{\circ} \mathrm{E}\right)$-first results, J. Atmos. Sol. Terr. Phys. 93, 21 $28,2013$.

Tarasick, D. W. and Hines, C. O.: The observable effects of gravity waves in airglow emission, Planet Space Sci., 38, 1105-1119, 1990.

Tarasick, D. W. and Shepherd, G. G.: Effects of gravity waves on complex airglow chemistries: $1 . \mathrm{O}_{2}\left(\mathrm{~b}^{1} \sum_{g}^{+}\right)$emission, J. Geophys. Res., 97, 3185-3193, 1992a.

Tarasick, D. W. and Shepherd, G. G.: Effects of gravity waves on complex airglow chemistries: 2. OH emission, J. Geophys. Res., 97, 3195-3208, 1992b.

Taylor, M. J., Turnbull, D. N., and Lowe, R. P.: Coincident imaging and spectrometric observations of zenith $\mathrm{OH}$ nightglow structure, Geophys. Res. Lett., 18, 1349-1352, 1991.

Taylor, M. J., Gardner, L. C., and Pendleton Jr. W. R.: Long-period wave signatures in mesospheric $\mathrm{OH}$ Meinel $(6,2)$ band intensity and rotational temperature at mid-latitudes, Adv. Space Res., 27, 1171-1179, 2001.

Vargas, F., Swenson, G., Liu, A., and Gobbi, D.: $\mathrm{O}\left({ }^{1} \mathrm{~S}\right), \mathrm{OH}$, and $\mathrm{O}_{2}$ (b) airglow layer perturbations due to AGWs and their implied effects on the atmosphere, J. Geophys. Res, 112, D14102, doi:10.1029/2006JD007642, 2007.

Viereck, R. A. and Deehr, C. S.: On the interaction between gravity waves and the $\mathrm{OH}$ Meinel (6-2) and $\mathrm{O}_{2}$ Atmospheric (0-1) bands in the polar night airglow, J. Geophys. Res., 94, 53975404, 1989.

Walterscheid, R. L. and Hickey, M. P.: One-gas models with heightdependent mean molecular weight: Effects on gravity wave propagation, J. Geophys. Res., 106, 28831-28839, 2001.

Walterscheid, R. L. and Schubert, G.: Dynamical-chemical model of fluctuations in the $\mathrm{OH}$ airglow driven by migrating tides, stationary tides, and planetary waves, J. Geophys. Res., 100, 17443 17449, 1995.

Walterscheid, R. L., Schubert, G., and Straus, J. M.: A dynamical chemical model of wave-driven fluctuations in the $\mathrm{OH}$ nightglow, J. Geophys. Res., 92, 1241-1254, 1987.

Walterscheid, R. L., Schubert, G., and Hickey, M. P.: Comparison of theories for gravity wave fluctuations in airglow emissions, J. Geophys. Res., 99, 3935-3944, 1994. 